\title{
Towards an efficient post Covid-19 ICT based extension service delivery model for the sugar industry of eSwatini
}

Dlamini, M.M ${ }^{1}$., Worth, S.H ${ }^{2}$ and Ajayi, O.A. ${ }^{3}$

Corresponding author: M. M. Dlamini. Email: mzmdlamini@gmail.com

\begin{abstract}
This study presents a designed ICT based extension service delivery system for the sugar industry of Eswatini. The model is an improvement of the current system and it presents a delivery system that is void of many limitations. This model emanates from findings of a survey which involved all smallholder sugarcane farmers $(N=172)$ and their extension officers $(N=17)$. The survey investigated how information and knowledge are currently managed within the sugar industry. Basically, the model revolves around the use of mobile phones to relay information among the sugar industry stakeholders in a timely, more organised, productive and cost-effective ways, without contravention of the COVID-19 pandemic protocols. Sugarcane stakeholders can now be able to exchange information using the model without having to meet physically, which is what most of the traditional approaches required. The exchange of information can be in a form of voiced, pre-recorded information in the form of texts, audio, or audio visuals. This would go a long way in enhancing smallholder farmer's productivity as it has the potential of empowering more rural sugarcane farmers with crucial information for improved productivity. The model has the potential to sustain itself as the participation of the stakeholders is promoted.
\end{abstract}

Key words: ICT, mobile phones, COVID-19, sugar industry

\section{INTRODUCTION}

The global impact of the COVID-19 pandemic is expanding daily. Governments around the world are faced with several challenges related to reducing the overall impact of the pandemic while ensuring sufficient food supplies and the functioning of services to those most in need. Between the current disruptions and future threats to the food supply chain, the COVID-19 outbreak has generated extreme vulnerability in the agriculture sector. It is, therefore, crucial to mobilize all available instruments, institutions and stakeholders from both public and private sectors and civil

\footnotetext{
${ }^{1}$ Lecturer. Department of Agricultural Education and Extension, University of Eswatini, P. O. Box Luyengo, M205. Email: mzmdlamini@gmail.com

${ }^{2}$ Associate Professor. Department of Agricultural Extension and Rural Resource Management. University of KwaZulu-Natal. Email: worths@ukzn.ac.za

${ }^{3}$ Professor. Department of Agricultural Education and Extension, University of Eswatini, P. O. Box Luyengo, M205. Email: ajayi@uniswa.sz
} 
society to ensure appropriate and timely response. Agricultural Extension and Advisory services (EAS) systems play an indispensable role at the frontline of the response to the pandemic in rural areas. However, to adapt to the emergency context within the government regulations, EAS providers need to rapidly change their way of operating.

For decades, the kingdom of Eswatini has continued to grow sugarcane for processing and subsequent export to various countries. This has provided employment opportunities to several Eswatini citizens and contributed immensely to the country's Gross Domestic Product (GDP). Through Eswatini Water and Agricultural Development Enterprise (ESWADE) the Eswatini government has been able to empower several smallholder farmers by building dams in the rural areas and facilitated the formation of farmer groups to embark on sugarcane production. This initiative has seen several smallholder farmers improving their livelihoods through the production of sugarcane especially in the Lowveld of Eswatini. The outbreak of the COVID-19 pandemic has adversely affected the sugarcane production value chain at all levels especially in information exchange as the nation had to lockdown to contain the spread of the virus.

Communication is central to agricultural extension and messages are the real information which is necessary in solving problems (Van den Ban, 2006). Man had always exchanged information even with the growing of sugarcane. Farmers in a given area may have produced a given crop for many years but with time as climate change kicks in, weather patterns and soil conditions change and the invasion of pests and diseases deviate from the norm, new information becomes the only solution for the farmers to adjust to such changes and even benefit from these changes. Developing better ways of farming such as the introduction of new varieties which perform much better than the original ones are some of the available options brought about by updated or new information. Omotayo and Adedoyin (2005) observed that farmers in developing countries are slow in recognizing the importance of information as well as the use of ICT to acquire knowledge, instead they have over relied on the use of extension agents. According to Van den Ban (2006), extension agents may be the most effective sources for farmers but obviously not the most efficient as evidenced by huge costs, extent of coverage and time. Recently, the outbreak of the corona virus has made it even more difficult for farmers to meet physically and exchange information.

This paper aimed at evolving a model that will use ICT in Eswatini to strengthen sugarcane extension services such that the barriers presented by the long distances between extension officers and famers for a physical encounter can be effectively cut down such that sugarcane farmers in the farthest and remote rural areas can exchange information with any sugar industry stakeholder without physical contact, thereby minimising the spread of the COVID-19 pandemic and the extra cost of travelling. This will also address the challenge of top to bottom nature of earlier approaches where information was flowing in one direction. With the suggested model, sugarcane farmers can originate queries, and get immediate response via mobile phones while within their workstations. 


\section{LITERATURE REVIEW}

Christoplos (2010:03) defines extension as "systems that facilitates the access of farmers, the organisation and other market actors to knowledge, information and technologies; facilitate their interaction with partners in research, education, agribusiness, and other relevant institutions; and assist them to develop their own technical, organisational and management skills and practices". This definition presents extension as responsible for facilitating farmer's access to information, knowledge and technology as well as developing their own skills and practices. These functions of extension can be efficiently executed by extension services personnel using relevant ICTs well supported by the environment in which they operate.

The extension strategy of the Eswatini sugar industry aims at improving yields and ensures sustainability through providing technology transfer and advisory services to sugarcane growers on all aspects of sugarcane production. This includes provision of advice about research findings to smallholder sugarcane growers and adoption of improved agricultural practises for increased productivity, profitability and sustainability (SSA, 2014/2015). These were attained through the short and medium strategies which include: the capacitation of extension officers to provide farm business management skills to the smallholder farmers; provision of a holistic extension service to growers and the continuous improvement in sucrose yield. The overall long-term perspective of extension according to the report aims at moving extension from supply driven (Scheduled) to demand (On request) driven extension. The Eswatini Sugar Association (ESA) expects that eighty percent of the smallholder sugarcane farmers should be able to make sound business management decisions within ten years of the strategy implementation. Salau, Saingbe, and Garba (2013) submitted that the time is now for the adoption of ICT by every stakeholder in agriculture to exchange relevant information in a more efficient way.

The introduction and subsequent use of ICTs by the sugarcane extension personnel and smallholder farmers could be an ideal vehicle that will enable this strategy to be implemented efficiently within the set time frame while maintaining the social distance which is crucial in reducing the spread of the corona virus. Debates have ensured on how ICT can assist in reducing poverty in developing nations (Heek, 1999). Samiullah and Rao (2003) noted that if ICTs are effectively implemented, they have the capacity to reduce poverty and enhance sustainable development, however, providing updated knowledge to smallholder farmers, especially those located in the remote poor areas can be challenging. ICTs have made such a challenging task manageable. For the smallholder sugarcane producer to improve production, new information that is accurate, reliable and presented timely is very crucial. 


\section{METHODOLOGY}

This article emanates from a study that investigated the influence of extension services using Information Communication and Technology (ICTs) to improve the productivity of smallholder sugarcane farmers, hence closing the productivity gap that exist between them and their large-scale counterparts. The study was a census, and a structured questionnaire was used to interview all the smallholder sugarcane farmers $(\mathrm{N}=172)$, as well as all the sugarcane Extension Officers from Government, ESA, Financial institutions and Parastatals $(\mathrm{N}=17)$ actively growing sugarcane in Eswatini during the year of data collection.

The study identified that the Eswatini sugar industry is equipped with characteristics that supports the use of ICTs by the sugar industry stakeholders to improve the productivity of smallholder sugarcane farmers (Dlamini and Worth, 2019). The study also discovered that these characteristics have not been fully harnessed for the benefit of smallholder farmers to optimise their productivity. The findings of the study revealed that both extension agents and smallholder sugarcane farmers perceived themselves as ready for the implementation and subsequent use of ICTs to facilitate information dissemination among themselves. Furthermore, the study revealed that both farmers and extension agents perceived what was regarded as barriers to the use of ICTs for information flow as not barriers to them (Dlamini and Worth, 2017). Finally, the study revealed the type of information that sugarcane farmers require as well as accurate and reliable sources that have the capability of relaying such information on time. The most efficient ways through which this information could be relayed were also identified.

\section{RESULTS AND DISCUSSIONS}

\subsection{The current sugarcane extension communication model}

Several institutions are responsible for the provision of advisory services and training to the sugarcane growers of Swaziland. These institutions include Eswatini Sugar Association (ESA), Eswatini Water and Agricultural Development Enterprise (ESWADE), Financiers, input suppliers and Government. Most of the communication with farmers around sugarcane production occurs through one or more of these institutions. Figure 1 depicts the current operational model in which sugarcane extension personnel is currently expected to relay information and knowledge between information generators and smallholder sugarcane farmers in Eswatini. Currently the process is completely manual. Extension officers are the ones who have the closest contact with the farmers. Most of the information they keep is on paper and maintained by each extension officer. This information is then translated to monthly reports that are submitted to the different extension mangers within the industry before they are included in the annual report. The process obviously suffers from severe paper-based issues such as duplication, redundancy or in case of diary being 
lost; there is a need to recapture the information from scratch. Each extension service provider (Finance, suppliers, ESA, Government) compiles its annual report that is independent of the other.

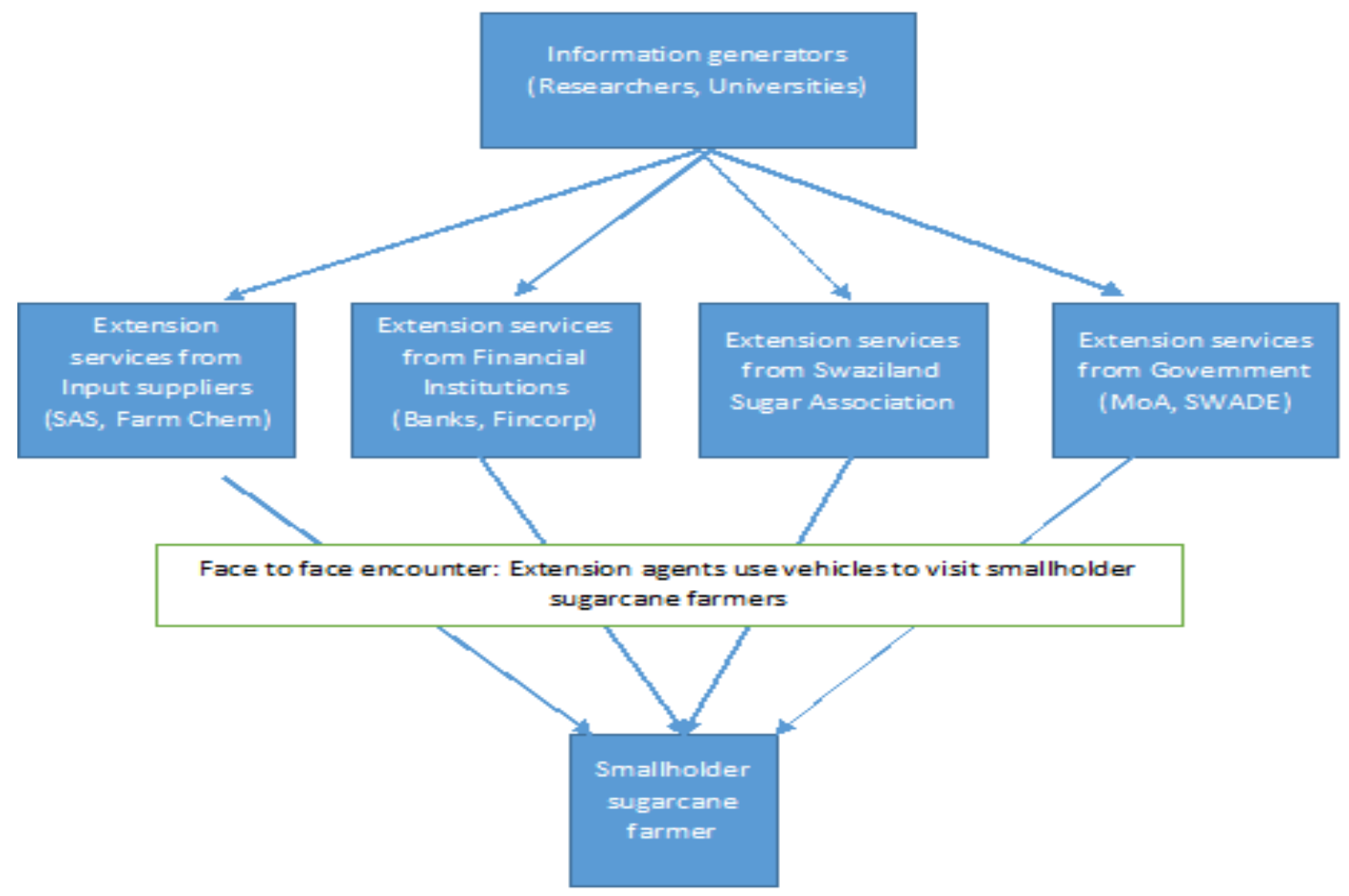

FIGURE 1: Current model for the sugar industry extension to deliver sugarcane production information to smallholder sugarcane farmers. (Dlamini and Worth, 2017)

Figure 1 shows that information and knowledge is disseminated through mainly the face-to-face method. Extension Agents are given vehicles and they travel from one sugarcane farmer to the next to disseminate or collect information related to sugarcane production following a predetermined schedule. This approach was grossly disrupted by the outbreak of COVID-19 pandemic. A lot of man-hours were lost as extension agents could not move freely during the lockdown which was put in place to curb the spread and more over this approach has a great potential of spreading the COVID-19 pandemic. Currently there is no system that supports an extension service delivery which coordinates the three domains which are; telecommunication, extension and Research for improved information dissemination, thereby increasing the productivity of smallholder farmers and maintaining social distancing amongst participants as a way of reducing the spread of the corona virus.

\subsection{Challenges of the existing extension system}

The method of communication presented in Figure 1 is presented with some challenges for both smallholder sugarcane farmers and extension officers. It is less demand-driven in that officers cannot give guidance to farmers as and when it is needed. Extension workers also do not reside 
with farmers within the community which reduces the frequency of information exchange among these stakeholders. In addition, extension services provided by governments are not effective due to inadequate funding. Diamond (1992) noted that the quality of extension in Eswatini is plagued by many factors; the major problems center on lack of clearly defined technical messages to be disseminated to most farmers. Oladele et al. (2009:317-318) found that the key strengths of Eswatini's extension service were that it had improved its extension systems and method, extension plans were highly feasible, and the setting of extension administration units was effective. The same study found that the greatest weaknesses of Eswatini's extension service were over-centralization of the budget for extension work and insufficient manpower.

In addition, Keregero (2000: 79) found that Eswatini's extension service was not contributing to any significant improvement in the livelihoods of farmers. The key cause of this were "a lack of a clearly defined philosophy, often leading to the use of top-down, directive methods; the extension job being male dominated and gender stereotyping; and most of the frontline extension workers being youthful, moderately experienced in their job and relatively lowly qualified". Communication institutions mandated to disseminate information were not trusted by farmers and are further hampered by insufficient extension personnel "leading to inequitable and infrequent coverage" (Keregero, 2000:79).

Most of the smallholder sugarcane farmers are sparsely located in the remote rural areas. Extension agents must travel long distances to reach them thereby attracting high travelling costs on fuel as well as increasing the risk of either spreading or catching the corona virus. Accessibility is a challenge due to poorly constructed roads which become worse during the rainy season. The frequency of visit to such areas by the extension agent is reduced by such factors thus depriving the farmer of crucial information. Farmers do not receive information on time and these results to poor decisions being taken out of ignorance which ultimately leads to poor yields. These poor and remote smallholder farmers have minimum sources where they can obtain information as and when they needed it (Diamond, 1992).

Eweg (2005) also observed that some smallholder sugarcane farmers are circumstantial farmers. These are farmers who joined the sugarcane production business not because they had the passion for the business but because they found themselves within the development project area where sugarcane needed to be grown. Therefore, Eweg (2005) noted that this kind of farmer needs a lot of extension support and motivation to be convinced that the sugarcane production business is viable. It becomes therefore difficult for such farmers to perform efficiently under this type of extension model. 


\subsection{Emergence of a better sugarcane extension communication model}

Sequel to the challenges associated with the existing model of communication, a new model is emerging from the modification in response to the challenges associated with the traditional model. The emerging model is a result of the study findings and it fits well to the country's telecom infrastructure. It aims at addressing the problems of converting extension information into digital form while at the same time allowing marginalised smallholder sugarcane farmers to have timely access to accurate information. It also fits well in the global strategies adopted by the World Health Organisation of social distancing as a way of reducing the spread of the corona virus.

The model presented in Figure 2 is designed as sugarcane extension communication model that aims at facilitating better communication between sugarcane farmers, information generators and extension officers. This model identifies three elements injected into the existing model to promote efficient and effective information dissemination among the sugar industry stakeholders via ICTs. The model introduced a tele-centre to be administered by ESA in conjunction with Eswatini Mobile Telephone Network (MTN) to coordinate all information between the different extension service providers and smallholder sugarcane growers. This will reduce travelling costs and physical contact with farmers and all other stakeholders thus reducing the problem of time lag caused by lockdown implemented by the government to stem the spread of the deadly pandemic.

Also proposed is that every stakeholder especially smallholder farmers and extension officers should possess mobile phone applications for exchange of sugarcane production information among themselves and other stakeholders, which is the case with the entire Eswatini sugar industry as indicated by Dlamini and Worth (2019). This will ensure that technical messages are relayed timely and effectively between famers and extension officers. Finally, the model requires sufficient network coverage in all the areas where sugarcane is grown to enable the use of mobile phones for information dissemination. Again, Dlamini and Worth (2019) found that almost every sugarcane growing area in Swaziland is covered with the mobile network which may require enhanced signal strength at some places. This will enable every farmer to have unlimited access to information disseminated via ICT as presented in the model. 


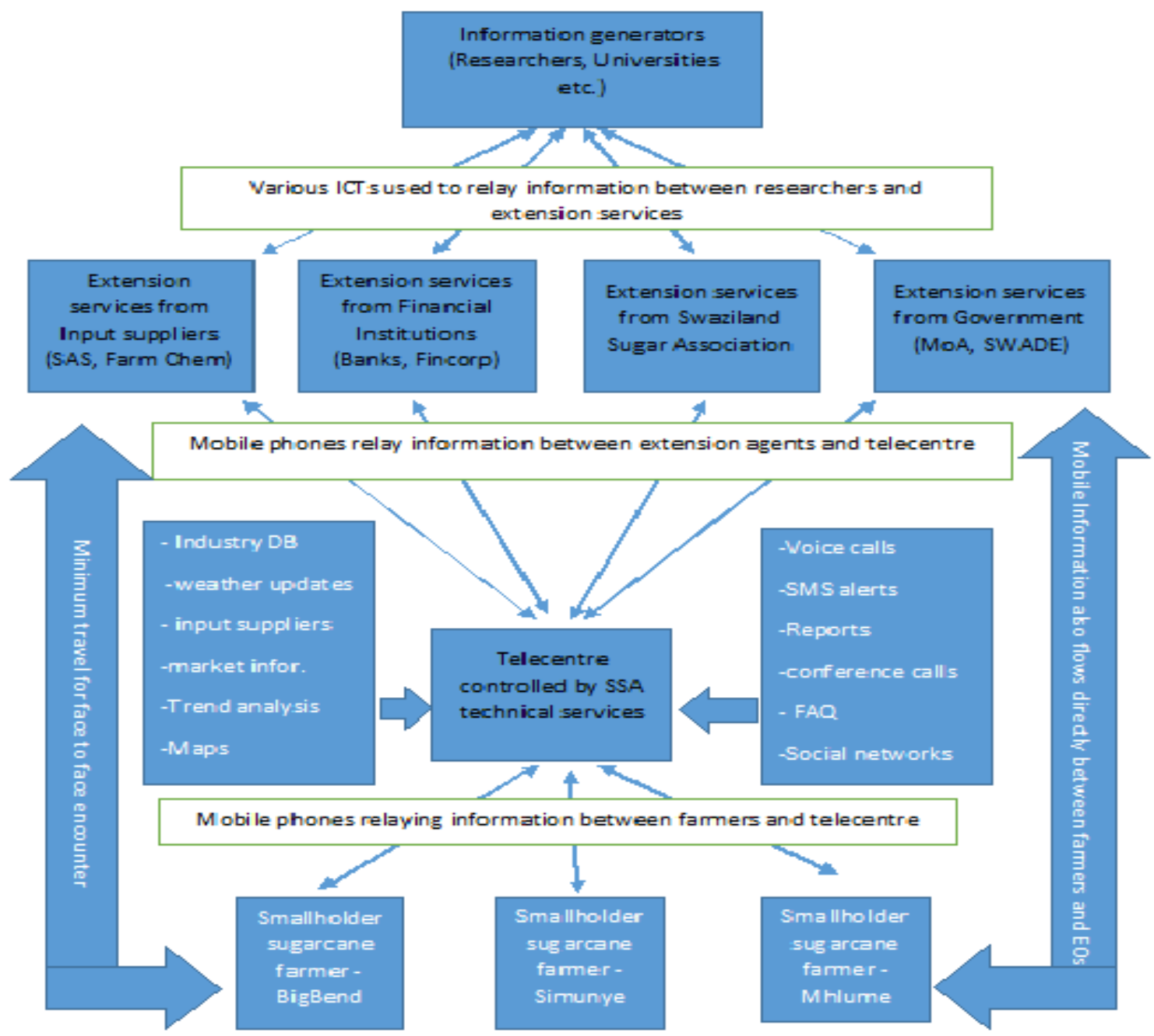

FIGURE 2: A refurbished model for the sugar industry extension to deliver sugarcane production information to smallholder sugarcane farmers

The interaction between rural farmers and extension officers via ICT within the tele-centre will be enhanced since there will always be people in the tele-centre who will facilitate the exchange of information thus giving both farmers and extension officers unlimited access to vital information. The main components of the model consist of firstly the user bases which are the sugarcane farmers, extension officers and institutional users. The second component is the user interface which consists of the mobile applications for farmers and extension officers as well as the webbased interface for institutional users. This model suggests creating an extension system that allows accurate and reliable information to be circulated timely via mobile phones among the industry stakeholders enabling everyone to possess adequate and up to date information for making accurate decisions on time. This would improve sugarcane productivity of smallholder farmers. 


\subsection{Mobile phones}

Despite their new entrance into remote agricultural communities, mobile phones are already assisting smallholder farmers in the rural remote areas to improve their agricultural activities. Advances throughout the mobile phone ecosystem have presented numerous advantages to smallholder sugarcane farmers which include:

- Access - most rural and remote areas of developing countries are experiencing an increase in mobile wireless networks and the number of people using mobile phones is on the increase.

- Affordability - the availability of affordable gadgets has made it possible for even rural smallholder farmers to own second hand mobile phones and use it to exchange information; and

- Applications - the available applications and services found in mobile phones start from simple text messaging services to increasingly advanced software applications. This application allows even the less skilled person in terms of operating the gadgets to be able to benefit from them. Making/receiving a call and sending text messages are some of the applications that are simple to operate.

The most common way through which mobile phones can enhance sugarcane production is through facilitating farmer exposure to less costly information. Where sugarcane production areas are remote with inaccessible roads, substituting phone calls for travel reduces time and cost burden for every sugar industry stakeholder. Sugarcane farmers who utilise mobile phones do save on travelling costs (Overå, 2006) and this effect is more real to those farmers that are in remote areas (Muto \& Yamano, 2009). It is not possible however, to completely avoid transport because extension officers do need to physically visit the farmers in field for real assessments and demonstrations.

Mobile phones are multifunctional devices ranging from regular phones to smart phones. Mobile phones do much more than simply placing a voice call. Table 1 summarises the various types of mobile technologies and their availability.

The capabilities of mobile phones are improving daily and information channels are converging. Smart phones and software applications provide advanced functionality such as conference calls, video conferencing, social media, GPS for mapping functionality, mobile money applications among others. Extension can now access many clients within a short space of time through mobile based learning platforms such as texts, pictures and short video clips which provide information to sugarcane farmers on how to improve their sugarcane production skills and knowledge. 
S. Afr. J. Agric. Ext.

Dlamini, Worth \& Ajayi

Vol. 49 No. 3, 2021: 31-45

http://dx.doi.org/10.17159/2413-3221/2021/v49n3a12842

(License: CC BY 4.0)

TABLE 1: Types and Availability of Mobile Technology

\begin{tabular}{|c|c|c|}
\hline TECHNOLOGY & DESCRIPTION & AVAILABILITY \\
\hline Voice & $\begin{array}{l}\text { The most basic channel; avoids most } \\
\text { literacy or linguistic barriers }\end{array}$ & Basic phones \\
\hline $\begin{array}{lll}\text { Short } & \text { Message } & \text { Service } \\
(\mathrm{SMS}) & & \\
\end{array}$ & $\begin{array}{l}\text { Ubiquitous text-based message limited to } \\
160 \text { characters }\end{array}$ & Basic phones \\
\hline $\begin{array}{l}\text { Unstructured Supplementary } \\
\text { Service Data (USSD) }\end{array}$ & $\begin{array}{l}\text { A protocol used by Global service for } \\
\text { mobile communications (GSM) phone to } \\
\text { communicate with the mobile network. }\end{array}$ & Basic phone \\
\hline Interactive Voice Response & $\begin{array}{l}\text { Computer programs that respond to the } \\
\text { voice input of callers }\end{array}$ & Basic phones \\
\hline $\begin{array}{l}\text { General Packet } \quad \text { Radio } \\
\text { Services (GPRS) }\end{array}$ & Low bandwidth data service & Mid-range phones \\
\hline $\begin{array}{l}\text { Software App (e.g. Java or } \\
\text { iOS) }\end{array}$ & $\begin{array}{l}\text { Preinstalled or downloaded software of } \\
\text { varied sophistication }\end{array}$ & Smartphones \\
\hline $\begin{array}{l}\text { Mobile wireless Application } \\
\text { Protocol (WAP) }\end{array}$ & A limited manner of browsing the internet & Mid-range phone \\
\hline $\begin{array}{ll}\text { Multimedia } & \text { Messaging } \\
\text { Service (MMS) } & \end{array}$ & $\begin{array}{l}\text { SMS-based technology to transmit } \\
\text { multimedia (Including images and video) }\end{array}$ & Mid-range phone \\
\hline Camera & For capturing still or moving pictures & Mid-range phone \\
\hline Bluetooth & $\begin{array}{l}\text { Protocol for transmitting data over short } \\
\text { distances }\end{array}$ & Mid-range phone \\
\hline Mobile web & Full-fledged web access & Smart phones \\
\hline $\begin{array}{l}\text { Global Positioning System } \\
\text { (GPS) }\end{array}$ & $\begin{array}{l}\text { Technology allowing for location-based } \\
\text { information }\end{array}$ & Smart phones \\
\hline
\end{tabular}

Source: $\quad$ https://www.crisscrossed.net/2009/11/01/the-many-potential-channels-for-mobileservices/

\subsection{The Information and communication Centre}

This is the main engine of the model and it consists of the technology centre, Infrastructure management, Knowledge management, helpline and the panel of experts. The technology centre is where information is given to farmers/extension officers via mobile phones. The information may vary from general issues regarding sugarcane production to more specific issues such as weather updates, control of sugarcane pests and diseases, market environment among others. The study has revealed that sugarcane farmers are heavy users of regular phones manufactured by Nokia and Samsung. Another advantage is that of collecting information from field for institutional users using mobile phones. This will ensure an efficient and accurate data collection process that 
will yield timely reports. This is also where there is infrastructure management, which involves the management of information exchange links (Internet and Phone).

The main objective of knowledge management is to produce meaningful information from the operational data and get useful results from it through providing more personalised, client oriented and crucial information forwarded straight to the famer's handsets. The knowledge generated will be for researchers, research users and policy makers. Help line will operate like a call centre and it will address sugarcane production problems that cannot be solved via mobile applications. For issues that cannot be answered by the helpline staff, the call will be re-directed to a conference call where an expert in the field will be asked to shed some light. Information from such discussions would be loaded in frequently Asked Questions (FAQ) database.

Panel of experts in sugarcane production would support the helpline staff. These will be knowledgeable extension officers already working in the field who will work as consultants for the helpline. Queries not addressed by the helpline will be forwarded to the appropriate research institutions. The extension agents are very important as they understand the language of researchers and the technical terminologies and could break it down to communicate well with the farmers in the language they could easily understand.

Specifically, the model aims at achieving the following:

- Provision of accurate, reliable and timely usable information among the sugar industry stakeholders. The information will be about mainly the information needs of smallholder sugarcane farmers as identified by Dlamini and Worth (2019). Such information will be distributed through mobile applications.

- Disseminating information in local language. This is easier for Swaziland as one national language is used and understood by every citizen of the country.

- Delivering voice-based content to the sugar industry stakeholders thus overcoming literacy barriers.

- Establishing a helpline backed by experts in the sugarcane growing field and providing advice within the shortest time possible.

- Improving agricultural extension by using specialized applications on mobile phones such as those applications that can aid in data collections for surveys conducted by research institutions.

- Creating a solid financial and technological base in terms of content.

\subsection{The project impacts}

The model presents potential for a fair access to information by sugarcane growers especially smallholder farmers. This will improve the ability of farmers to make accurate and informed decisions thus improving their productivity. The process of collecting data using mobile phones 
will lower infrastructure costs, remove transportation costs, increase accuracy and also help in the monitoring of field staff. The project output will have an influence towards policy making and enhance the working standards of extension officers.

\subsection{Opportunities offered by the model}

The model can assist the sugar industry stakeholders have access to up-to-date information and guidance from different reliable sources. These sources may include extension officers, other farmers, researchers and agricultural database websites among others. Requests are forwarded to the information communication centre where appropriate responses are generated by relevant researchers. This approach is different from the traditional one (Overå, 2006) where all queries are managed by one agricultural expert.

\subsubsection{Unlimited exposure to information}

Another important feature of the model is its ability to stimulate farmer driven extension whereby farmers initiate request for guidance and assistance based on their unique needs. This model also ensures that farmers get real time response to their requests; they do not have to wait for longer periods to submit their request which was the case with the traditional model when the extension officers were expected to visit them. The demands can be made almost immediately when there is need for it (Overå, 2006).

\subsubsection{Cost effectiveness}

The model is also potentially cost effective as the costs can be distributed to all the industry stakeholders so that it is shared equally. This will make even smallholder sugarcane farmers be able to contribute towards this project. The design is also self-sustainable as all the services it provides could be charged at a minimum fee. Donor agencies could also be encouraged to finance projects that are aimed at improving the productivity of smallholder rural farmers.

\subsection{The challenges and ways to minimize the effects}

This section of the paper highlights some of the possible challenges of the model and discusses how their effects could be minimized.

\subsubsection{Illiteracy}

Illiteracy has always been a challenge when it comes to technology adoption. This is especially very true when the technology has to do with information exchange. For instance, people who use their mobile phones for voice communication are more than those who use the mobile phones for text messaging functionality. New applications have been put in places that have the capacity to recognise voices. These applications are ideal for the illiterate population so that they can have access to information on "voice sites" (and not websites) in audio format. 


\subsubsection{Power supply requirement}

All ICT tools need electricity to operate. However, as observed earlier in this study, Swaziland has embarked on a project of rural electrification which has seen the entire sugar belt receiving a complete coverage. This however could be supplemented using solar panels during the day.

\subsubsection{Funding}

The funding needed to operate this model are in two parts: the establishment cost and the maintenance costs. These could be provided by a collaboration of the Eswatini Cane Growers Association, Eswatini Millers Association, sponsors and the government of Eswatini.

\section{CONCLUSIONS AND RECOMMENDATIONS}

Countries all over the world are engaged in national development and this objective is recommendable because people's lives are ultimately enhanced. For any country to achieve this objective, it must start this development at grass roots by first engaging agriculture and rural development. The first and important step towards this idea is the development of human resources by building their capacity to engage in productive agriculture by deploying innovations and technology. This could be done via the use of mass media channels. In Eswatini, where sugar production is an economic activity, it is important to maintain a good balance in the dissemination of information among the sugar industry stakeholders to harness the full potential of rural populace towards attaining national development.

Farming in a sustainable manner is both knowledge intensive (Garforth \& Lawrence, 1997) and information demanding compared to conventional methods, because skills effectively takes the space of external inputs (Garforth \& Lawrence, 1997; Pretty, 1995). In essence, the roles of knowledge, information, technologies, skill and attitudes in sustainable agriculture cannot be overstated and sustainable farming would necessarily be best supported by extension through implementation of programmes aimed at building capacity among farmers. In sum, the model could be adopted to achieve a strong and healthy agricultural extension delivery system in the sugar industry of Eswatini.

This model will no doubt assist the extension workers access more farmers in a cost-efficient manner with minimum contact as required in the post lockdown protocol advocated by the World Health Organisation to stem the spread of COVID-19. To achieve this, the following recommendations are made:

- This model should be subjected to continuous evaluation to keep improving the model.

- All the sugar industry stakeholders, especially the smallholder farmers should be trained on the use and benefits of the model.

- Pilot sites could be established in various locations of the country (e.g., in the three sugar mills of the country) to assess its effectiveness. 
- The search for sponsorship should be undertaken where potential donors and government agencies should be requested to finance the project.

\section{REFERENCES}

CHRISTOPLOS, I., 2010. Mobilizing the potential of rural and agricultural extension.

DIAMOND, J.E., 1992. Agricultural extension in Swaziland: An evolution. Conference Proceedings of the Symposium for Research in Agricultural and Extension Education. Agricultural and Extension Education: Preparing for the $21^{\text {st }}$ Century. Columbus, OH: The Ohio State University.

DLAMINI, M.M. \& WORTH, S.H., 2019. Readiness of the Swaziland sugar industry towards the use of ICT specifically cell phones to access information: perceptions of smallholder sugarcane farmers and extension officers. South African Journal of Agricultural Extension, 47(3): 92-107.

DLAMINI, M.M. \& Worth, S.H., 2017. Barriers to Sugarcane Production Information Access via ICT: Perceptions of Extension Officers and Smallholder Sugarcane Growers in Swaziland. Asian Journal of agricultural extension, Economics and Sociology. 21(2):1- 13.

EWEG, M., 2005. The changing profile of smallholder 'sugarcane'farmers in South Africa. Unpublished paper, South African Sugarcane Research Institute, Mount Edgecombe, South Africa.

GARFORTH, C. \& LAWRENCE, A., 1997. Supporting sustainable agriculture through extension in Asia. Natural Resource Perspectives, 21.

HEEK, R., 1999. Information and Communication Technologies, Poverty and Development. Development informatics Working Paper Series, Paper No5, June 1999, IDPM, Manchester.

KEREGERO, K.J.B., 2000. Reaching Swazi nation land farmers: challenges to the credibility of agricultural extension in Swaziland. UNISWA Journal of Agriculture, 9: 79-89.

MUTO, M. \& YAMANO, T., 2009. The impact of mobile phone coverage expansion on market participation: Panel data evidence from Uganda. World Development, 37(12): 1887-1896.

OLADELE, O.I., LEPETU, J., SUBAIR, S.K. OBUH, J., 2009. SWOT analysis of extension systems in Southern African countries. Journal of Agriculture and Environment for International Development 2009, 103 (4): 309-32.

OMOTAYO, A. \& ADEDOYIN, S., 2005. Information Communication Technology (ICT) and Agricultural Extension: Emergency issues in transferring agricultural technology in developing countries. Agricultural Extension in Nigeria. Ilorin: Agricultural Extension Society of Nigeria. 
OVERÅ, R., 2006. Networks, distance, and trust: Telecommunications development and changing trading practices in Ghana. World Development, 34(7): 1301-1315.

PRETTY, J.N., 1995. Regenerating agriculture: policies and practice for sustainability and selfreliance: Joseph Henry Press.

SALAU, E., SAINGBE, N. \& GARBA, M., 2013. Agricultural Information Needs of Small Holder Farmers in Central Agricultural Zone of Nasarawa State. Journal of Agricultural Extension., 17(2): 113-121.

SAMIULLAH, Y. \& RAO, S., 2003. Role of ICTs in urban and rural poverty reduction. DFID. SSA. (2014/2015). Annual Report. Mbabane. Swaziland.

VAN DEN BAN, A.W., 2006. World trend in agricultural extension. Paper presented at the Proceedings of the 2nd international conference of agriculture, education and environment held October 13-16, 2004 at the Rural Development Administration, Suwon, Korea. 